NASA

Technical Memorandum 103673 $p 7$

AVSCOM

Technical Report 90-C-030

\title{
Two Reference Time Scales for Studying the Dynamic Cavitation of Liquid Films
}

D.C. Sun

State University of New York at Binghamton

Binghamton, New York

and

David E. Brewe

Propulsion Directorate

U.S. Army Aviation Systems Command

Lewis Research Center

Cleveland, Ohio

Prepared for the

1991 Cavitation Symposium at the Joint ASME/JSME

Fluids Engineering Conference

Portland, Oregon, June 23-26, 1991

\section{NASA}

(NASA-TY-103673) THO RFFERENCE TIME SCALFS

FOR STUDYING THE DYNAMIC CAVITATION UF

LIQUID FILMS (NASA) $7 \mathrm{p}$ CSCL 200

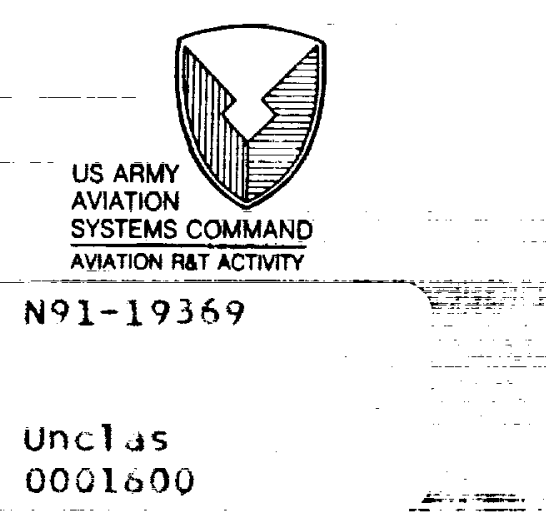


TWO REFERENCE TIME SCALES FOR STUDYING THE DYNAMIC CAVITATION OF LIQUID FILMS

\author{
D.C. Sun* \\ Department of Mechanical and Industrial, Engineering \\ Thomas J. Tatson School of Engineering, \\ Applied Science, and Technology \\ State University of New York at Binghamton \\ Binghamton, New York 13902-6000 \\ and \\ D. E. Brewe* \\ Propulsion Directorate \\ U.S. Army Aviation Systems Command \\ Lewis Research Center \\ Cleveland, Ohio $\$+135$
}

ABSTRACT

Two formulas, one for the characteristic time of filling a void with the vapor of the surrounding liquid, and one of filling the void by diffusion of the dissolved gas in the liquid, are derived. Based on this analysis, it is seen that in an oil film bearing operating under dynamic loads, the content of the cavitation region should be oil vapor rather than the air liberated from solution, if the oil is free of entrained air.

\section{NOMENCLATURE}

C mass concentration of gas

$\mathrm{C}_{S}$ saturation value of $\mathrm{C}$

D coefficient of binary diffusion

H Henry's constant

h thickness of liquid film

$j_{\text {cond number of molecules condensing on unit surface }}$ area in unit time

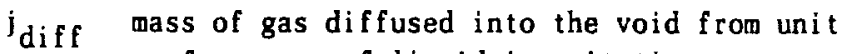
surface area of liquid in unit time

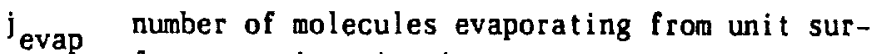
face area in unit time

k Boltzmann constant, $=1.380622 \times 10^{-23} \mathrm{~J} / \mathrm{K}$

$\ell$ thickness of diffusion layer

$M$ molecular weight

II mass of a molecule

n number of molecules in unit volume

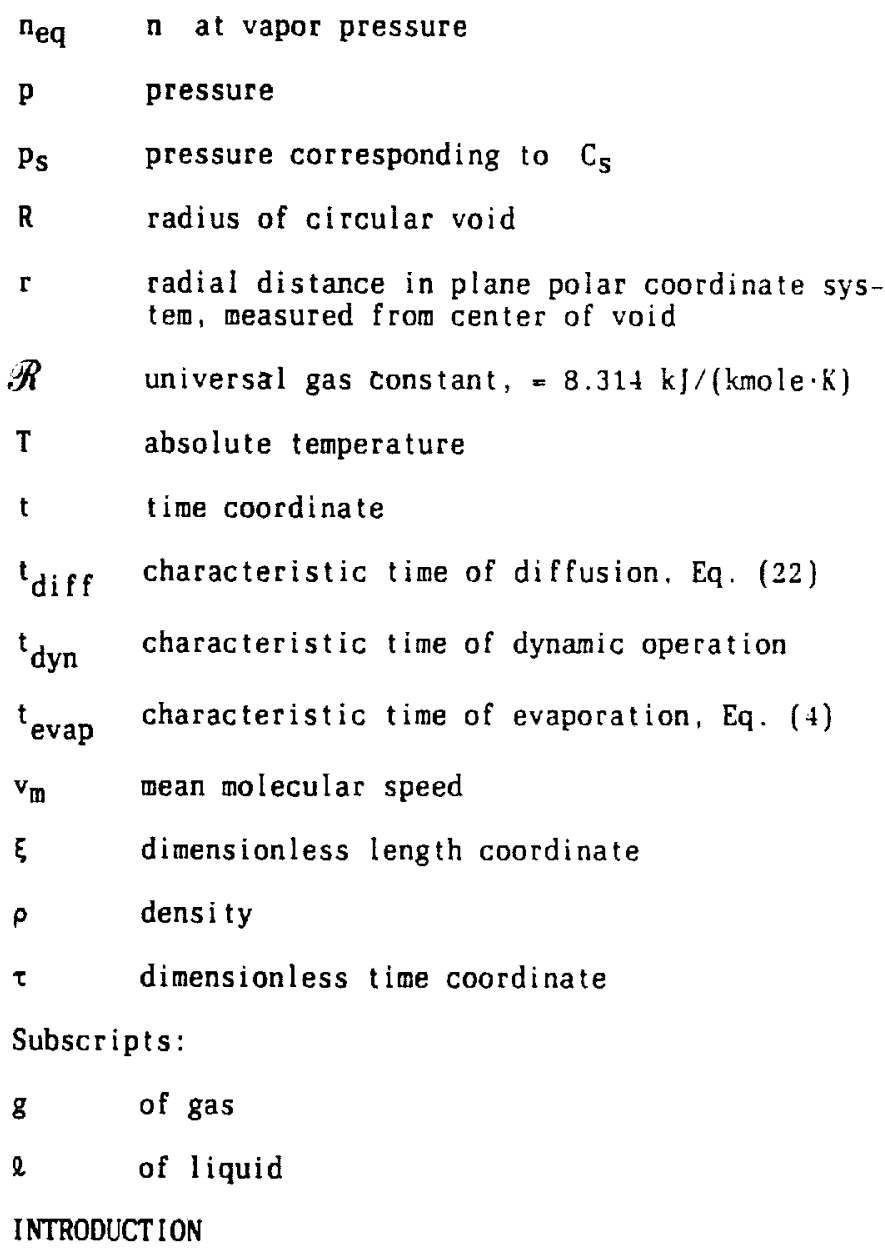

The cavitation of oil films in bearings operating under dynamic loads is not well understood. One of the unresolved questions is whether the cavitation bubble

* Member, ASME. 
contains air, or vapor, or is just an empty void. This question is closely tied with the behavior of the bubble, e.g., whether it collapses or sustains itself during the high pressure portion of the pressure cycles. Understanding the bubble behavior is indispensable to the construction of a sound theory of dynamically loaded bearings. At present, reliable design information is still lacking for important applications of dynamically loaded bearings, such as the squeeze film damper.

Air and vapor cavities arise in oil film bearings in several ways (Dowson and Taylor, 1979). Air from the surrounding atmosphere may be entrained in oil when subambient pressure occurs in the bearing clearance; the dissolved air in oil may be liberated when the pressure falls below the saturation pressure of the solution; and oil molecules may evaporate when the pressure falls to the vapor pressure of oil. Air entrainment is device dependent; it can be dealt with only according to specific circumstances. On the other hand, liberation of dissolved air and oil evaporation are processes dependent only on fluid properties; they can be treated in general terms. In the following, the latter two processes are analyzed and their respective time scales determined. By comparing these time scales with that of bearing operation, one can judge the relevance of these processes with reference to the cavitation in dynamically loaded bearings.

\section{CHARACTERISTIC TIME OF EVAPORATION}

Consider that a void is suddenly created in a liquid film, the molecules start to evaporate from the liquid surface into the void. After some time, the pressure in the void is built up to the vapor pressure of the liquid, which signifies the equilibrium between the flux of evaporation and flux of condensation. The vapor pressure of the liquid is assumed low. Hence, one may consider (Langmuir, 1913) that the flux of evaporation is independent of the presence of vapor in the void; and that the flux of condensation is likewise not affected by the flux of evaporation, and is determined only by the pressure in the void. Since the flux of molecules is one-fourth the number density times mean molecular speed (Present, 1958, p. 22), one may write:

$$
j_{\text {evap }}=\frac{1}{4} n \mathrm{eq}^{\mathrm{m}} \mathrm{w}^{\prime} \quad \mathrm{j}_{\text {cond }}=\frac{1}{4} \mathrm{nv}_{\mathrm{m}}
$$

Consider that the film has thickness $h$ and the void is circular with radius $R$. Then, the change in the number density in the void may be expressed as:

$$
\pi R^{2} h \frac{d n}{d t}=2 \pi R h\left(j_{\text {evap }}-j_{\text {cond }}\right)
$$

Combining Eqs. (1) and (2), one obtains:

$$
\frac{\mathrm{dn}}{\mathrm{dt}}=\frac{\mathrm{n}_{\mathrm{eq}}-\mathbf{n}}{\mathrm{t}_{\text {evap }}}
$$

where

$$
t_{\text {evap }} \equiv \frac{2 R}{v_{m}}
$$

The solution to Eq. (3) satisfying the initial condi$t$ ion $n(0)=0$ is:

$$
\frac{n}{n_{e q}}-1-e^{-t / t} \text { evap }
$$

The parameter tevap signifies the time needed to build up the pressure in the void to 63 percent of the vapor pressure, and may be taken as the characteristic time of evaporation. It is interesting to see from Eq. (4) that tevap is essentially the time a molecule takes to travel across the void, and is independent of the vapor pressure of the Iiquid. With the mean molecular speed given as (Present, 1958, p. 78)

$$
v_{m}=\left(\frac{8 k T}{\pi m}\right)^{1 / 2}
$$

which is based on the Maxwell distribution, this characteristic time can be readily calculated.

In the following, an oil-like substance, squalene, of known molecular structure (Morales and Buckley, 1988) is used for the calculation. The needed properties of squalene are given in Table 1. From the observation of the cavitation in a dynamically loaded bearing (Sun and Brewe, 1990), the cavitation region was large and covered a fraction of the bearing surface. If the typical size of the cavitation bubble is taken to be $R=10$ mn and the operating temperature to be $T=293 \mathrm{~K}$, then Eqs. (6) and (4) yield $v_{m}=120 \mathrm{~m} / \mathrm{s}$ and $t_{\text {evap }}=0.167 \mathrm{~ms}$.

\section{CHARACTERISTIC TIME OF DIFFUSION}

The solubility of gas in liquid is given by Henry's law:

$$
\frac{\frac{C}{M_{g}}}{\frac{C}{M_{g}}+\frac{\rho_{\ell}}{M_{\ell}}}=\frac{p}{H}
$$

which states that the mole fraction of the gas in the solution is proportional to the pressure of the gas outside the solution. The coefficient appearing in this relation is called Henry's constant whose value depends on the particular combination of gas and liquid. Henry's law applies to weak solutions, i.e.,

$$
\frac{C}{M_{g}} \ll \frac{\rho_{\ell}}{\bar{M}_{\ell}}
$$

Hence, Eq. (7) may be written approximately as:

$$
\frac{\frac{C}{M_{g}}}{\frac{\rho_{l}}{M_{Q}}}=\frac{g}{H}
$$

Consider a liquid film saturated with a dissolved gas. According to Eq. (9), the saturation concentration and the corresponding saturation pressure ps are related by:

$$
\frac{\frac{C_{s}}{M_{g}}}{\frac{P_{\ell}}{M_{\ell}}}=\frac{p_{S}}{H}
$$


Let a circular void of radius $R$ be suddenly created in the film and the dissolved gas start to diffuse into the void. It is intended to find how the pressure in the void increases with time.

The variation of gas concentration in the solution is governed by the diffusion equation:

$$
\frac{1}{r} \frac{\partial}{\partial r}\left(r \frac{\partial C}{\partial r}\right)=\frac{1}{D} \frac{\partial C}{\partial t}, \quad R<r<\infty
$$

The initial condition is:

$$
C(r, 0)=c_{s}
$$

The boundary condition at large distance from the void is :

$$
C(\infty, t)+C_{s}
$$

With $p(t)$ denoting the pressure in the void, Eq. (9) is applied as the boundary condition at $r=R$. let $t$ dyn be a representative duration for the occurrence of cavitation, and $l$ the characteristic size of the region where diffusion effectively takes place. From Eq. (10) one deduces that

$$
\ell=\left(D t_{d y n}\right)^{1 / 2}
$$

For a gas-in-liquid system, typically $D \sim 0\left(10^{-9}\right.$ $\left.\mathrm{m}^{2} / \mathrm{s}\right)$; and in the operation of dynamically loaded bearings, typically tdyn $\sim 0\left(10^{-2} \mathrm{~s}\right)$. Then Eq. (13) shows that $\ell \sim 0\left(10^{-6} \mathrm{~m}\right)$. Hence, diffusion is ef ective oniy in a thin layer whose thickness is much smaller than $R$. Substituting

$$
\begin{array}{ll}
\mathbf{r}=\mathrm{R}+\ell \xi, & \xi \sim 0(1) \\
\mathrm{t}=\mathrm{t}_{\mathrm{dyn}} \tau, & \tau \sim O(1)
\end{array}
$$

into Eq. (10) and retaining only the leading order terms, one obtains:

$$
\frac{\partial^{2} \mathrm{C}}{\partial \xi^{2}}=\frac{\partial \mathrm{C}}{\partial \tau}
$$

The initial and boundary conditions are transformed into:

$$
\left.\begin{array}{ll}
\text { At } \tau=0, & \mathrm{C}=\mathrm{C}_{s} \\
\text { As } \xi \rightarrow \infty, & \mathrm{C} \rightarrow \mathrm{C}_{s} \\
\text { At } \xi=0, & \frac{\frac{\mathrm{C}}{\mathrm{M}_{\mathrm{g}}}}{\frac{\rho_{\ell}}{M_{\ell}}}=\frac{\mathrm{p}}{\mathrm{H}}
\end{array}\right\}
$$

The solution to this system can be readily found. In terms of the original variables, it is:

$$
\frac{C}{C_{s}}=1-\left(1-\frac{D}{P_{S}}\right)\left\{1-\operatorname{erf}\left[\frac{r-R}{2(D t)^{1 / 2}}\right]\right\}
$$

This is an approximate solution because during its derivation $p(t)$ is treated as constant. This quasisteadiness approximation can be justified by the final result, which will show that $p$ is indeed a slowly varying function during the diffusion process. law:

The mass flux into the void is given by Fick's

$$
\mathfrak{j}_{\text {diff }}=D\left(\frac{\partial C}{\partial r}\right)_{r=R}
$$

Using Eq. (17) to evaluate the concentration gradient, one finds:

$$
j_{\text {diff }}=c_{s}\left(1-\frac{p}{p_{s}}\right)\left(\frac{D}{\pi t}\right)^{1 / 2}
$$

The change of the gas density in the void may then be expressed as :

$$
\pi R^{2} h \frac{d \rho}{d t}=2 \pi R h j_{d i f f}
$$

It is assumed that the gas in the void obeys the ideal gas law:

$$
p=\frac{p}{H_{g}} \mathscr{h} T
$$

In addition, a paraneter $t_{\text {diff }}$ is defined to simplify the notation:

$$
t_{\text {diff }} \equiv \frac{\pi}{16}\left(\frac{U_{\ell} H}{\rho_{\ell} \mathcal{R} \mathrm{T}}\right)^{2} \frac{R^{2}}{D}
$$

Substituting Eqs. (9a), (19), (21), and (22) into (20). one obtains the equation governing $p$ :

$$
-\frac{d p}{d t}=\frac{p_{s}-p}{2\left(t_{d i f f}\right)^{1 / 2}}
$$

The solution to this equation satisfying the initial condition $\mathrm{p}(0)=0$ is:

$$
\left.\frac{p}{p_{s}}=1-e^{-(t / t} \text { diff }\right)^{2}
$$

The parameter $t$ diff signifies the time needed for the pressure in the void to reach 63 percent of $p_{s}$, and may be taken as the characteristic time of diffusion. Its evaluation requires the knowledge of the coefficient of binary diffusion and Henry's constant. For air in squalene, these quantities are found (Appendix) to be $\mathrm{D}=0.495 \times 10^{-9} \mathrm{~m}^{2} / \mathrm{s}$ and $\mathrm{H}=13.4 \mathrm{MPa}$. Again by taking $R=10 \mathrm{~mm}$ and $T=293 \mathrm{~K}$, one obtains from Eq. (22) that $t_{\text {diff }}=0.324 \times 10^{6} \mathrm{~s}$.

\section{DISCUSSION}

The characteristic time of diffusion calculated in the above example appears unexpectedly long, and warrents a comparison with the results of similar studies in the literature. Epstein and Plesset (1950) calculated the time of completely dissolving a spherical air bubble in water. In their analysis the concentration of air at the bubble wall was assumed always saturated $\left(C_{s}\right)$, and that in water $\left(C_{i}\right)$ was treated as a parameter. The dissolving time was expressed as a function of the concentration ratio $\left(C_{i} / C_{s}\right)$ and the initial 
bubble radius $\left(R_{0}\right)$. In the case of $C_{i}=0$, where diffusion was the fastest, the dissolving time was found to be $1.25 \mathrm{~s}$ for $R_{0}=0.01 \mathrm{~mm} ; 1.25 \times 10^{2} \mathrm{~s}$ for $R_{0}=0.1$ and and $1.25 \times 10^{4}$ s for $R_{0}=1 \mathrm{~mm}$. Recognizing from Eq. (22) that $t_{\mathrm{diff}}$ is proportional to the square of the bubble radius, one would expect a dissolving time of $O\left(10^{6} \mathrm{~s}\right)$ for a bubble radius of $10 \mathrm{~mm}$. Krieger, Mulholland, and Dickey (1967) actually measured the dissolving time. For oxygen bubbles of initial radi in the neighborhood of $0.3 \mathrm{~mm}$, they observed the dissolving time to vary from $6 \times 10^{2} \mathrm{~s}$ to $0.45 \times 10^{4} \mathrm{~s}$, for $C_{i}$ ranging between zero and 90 percent of saturation. Thus, the credibility of Eq. (22) is supported by these earlier results; they all point to the fact that diffusion is a very slow process.

The load frequencies encountered in current oil film bearings fall in a certain range. The operating speed of the squeeze $\mathrm{film}$ dampers in gas turbine engines may be as high as a few ten-thousand revolutions per minute; while that of the main and connecting rod bearing in reciprocating internal combustion engines may be as low as a few hundred revolutions per minute. This range of operating speeds corresponds to a $t_{\text {dyn }}$ value from $1 \mathrm{~ms}$ to $0.1 \mathrm{~s}$. Thus, ${ }^{t}$ dyn is usually much longer than the characteristic time of evaporation, and one may expect the presence of oil vapor in the cavitation bubble. On the other hand, tdyn is much too short compared with the characteristic time of diffusion. Hence, there is not enough time for the dissolved air to come out of the solution and find its way into the cavitation bubble. This analys is is consistent with the experimental results of Sun and Brewe (1990), where no difference in the cavitation pattern was observed between the degassed and the aerated oil throughout the cases studied. Since the diffusion of dissolved air does not play a role in the dynamic cavitation phenomenon, then, whether the oil has dissolved air in it or not should make no difference.

It has of ten been reported ${ }^{1}$ that, under dynamic bearing loads, persistent and numerous gas bubbles were found in the oil film, which eventually became a wellmixed two-phase fluid. The presence of these gas bubbles has been attributed to both the liberation of dissolved gases in oil and the entrainment of ambient air. It seems clear that the former suspected cause can be ruled out by the result of the present analysis.

\section{CLOSURE}

Two formulas (Eqs. (4) and (22)) are derived which can be used conveniently to determine, respectively, the characteristic time of filling a void with the vapor of the surrounding liquid, and that of filling a void by diffusion of the dissolved gas in the liquid. These time scales can be compared with the characteristic time of bearing operation to determine the relevance of these processes with reference to the dynamic cavitation in oil film bearings.

The computation shows that the evaporation process is usually fast enough to fill the cavitation bubble with oil vapor: whereas the diffusion process is much too slow for the dissolved air to liberate itself and enter the cavitation bubble.

\section{ACKNOWLEDGMENTS}

The authors are indebted to Mr. Wilfredo Morales of NASA Research Center for providing them a guided tour to the Chemists' wonderland of diffusion. D.C. Sun is particularly grateful to Dr. Edward J. Bisset t of the General Motors Research Laboratories for his timely objection to an earlier, incorrect derivation in the work.

\section{REFERENCES}

Dowson, D., and Taylor, C.M., 1979, "Cavitation in Bearings - Lubricating Films", Annual Review of Fluid Mechanics, Vol. 11, pp, 35-66.

Epstein, P.S., and Plesset, M.S., 1950, "On the Stability of Gas Bubbles in Liquid-Gas Solutions," Journal of Chemical Physics, Vol. 18, pp. 1905-1909.

Krieger, I.M., Mulholland, G.I., and Dickey, C.S., 1967. "Diffusion Coefficients for Gases in Liquids from the Rates of Solution of Small Cas Bubbles," Journal of Physical Chemistry, Vol. 71, pp. 1123-1129.

Langmuir, I., 1913, "The Vapor Pressure of Metallic Tungsten," Physical Review, Vol. 2, pp. 329-3 $\$ 2$.

Morales, N., and Buckley, D.H., 1988, "Concentrated Contact Sliding Friction and Wear Behavior of Several Ceramics Lubricated with a Perfluoropolyalkylether at $25{ }^{\circ} \mathrm{C}$," Wear, Vol. 123, pp. 345-354.

Osburn, J.0., and Markovic, P.L., 1969, "Calculating Henry's Law Constant for Gases in Organic Liquids." Chemical Engineering, Vol. 76, August 25, pp. 105-108.

Present, R.D., 1958, Kinetic Theory of Gases, McGraw Hill.

Simons, J., and Ponter, A.B., 1975, "Semi-Empirical Formulae for the Prediction of Diffusion in Liquid Systems," The Canadian Journal of Chemical Engineering, Vol. 53, October, pp. 541-550.

Sun, D.C., and Brewe, D.E., 1990, "A High-Speed Photography Study of Cavitation in a Dynamically Loaded Journal Bearing," NASA TM-103178.

White, D.C., 1970, "Squeeze Film Journal Bearings," Ph.D. Thesis, Cambridge University.

\section{APPENDIX}

\section{CALCULATING D AND $H$ FOR THE SOLUTION OF AIR IN} SQUALENE

Some needed properties of air and squalene are listed in Table 1. The coefficient of binary diffusion for gas in liquid may be calculated by using the Arnold equation (Simons and Ponter, 1975) which reads:

$$
D=\frac{0.010\left(\frac{1}{H_{g}}+\frac{1}{H_{\ell}}\right)^{1 / 2}}{u_{\ell}^{1 / 2}\left(v_{g}^{1 / 3}+v_{\ell}^{1 / 3}\right)^{2}}
$$

where the empirical constant 0.010 is accurate at $20{ }^{\circ} \mathrm{C}$; the units of the quantities on the RHS of the equation are as shown in Table 1 ; and $D$ is in $\mathrm{cm}^{2} / \mathrm{s}$. Substituting the appropriate values of Table 1 into the equation, one obtains $D=0.495 \times 10^{-5} \mathrm{~cm}^{2} / \mathrm{s}$.

Henry's constant can be estimated by the method of Osburn and Markovic (1969). The procedure is to first calculate a parameter "parachor" for the liquid based on its molecular structure. From the parachor and the liquid's molal volume, its surface tension can be evaluated. Then from empirical correlations an 0stwald coefficient is obtained, which can be converted to Henry* $s$ constant in unit of atmospheres. Following this procedure and with the use of Table 1, one obtains $H=132$ atmospheres. 
TABLE 1. - SOME PROPERTIES OF AIR AND SQUALENE

\begin{tabular}{|c|c|c|}
\hline & Air & Squa lene \\
\hline $\begin{array}{l}\text { Molecular weight } \\
\text { Mass of a molecule } \\
\text { Densi ty } \\
\text { Molal volume (at boil- } \\
\text { ing temperature) } \\
\text { Absolute viscosity } \\
\text { Parachor }\end{array}$ & $\begin{array}{l}\mathrm{M}_{\mathrm{g}}=28.97 \mathrm{~g} / \mathrm{mole} \\
\mathrm{V}_{\mathrm{g}} \approx 30 \mathrm{mI} / \mathrm{mole}\end{array}$ & $\begin{aligned} \mathrm{M}_{\mathrm{t}} & =422.8 \mathrm{~g} / \mathrm{mole} \\
\mathrm{m} & =70.2 \times 10^{-23} \mathrm{~g} \\
\rho_{\mathrm{t}} & =0.81 \mathrm{~g} / \mathrm{ml} \\
\mathrm{V}_{\mathrm{t}} & =522 \mathrm{ml} / \mathrm{mole} \\
\mu_{\mathrm{t}} & =9.72 \mathrm{cP}\left(\text { at } 20^{\circ} \mathrm{C}\right) \\
{[\mathrm{P}] } & =1160.3\end{aligned}$ \\
\hline
\end{tabular}




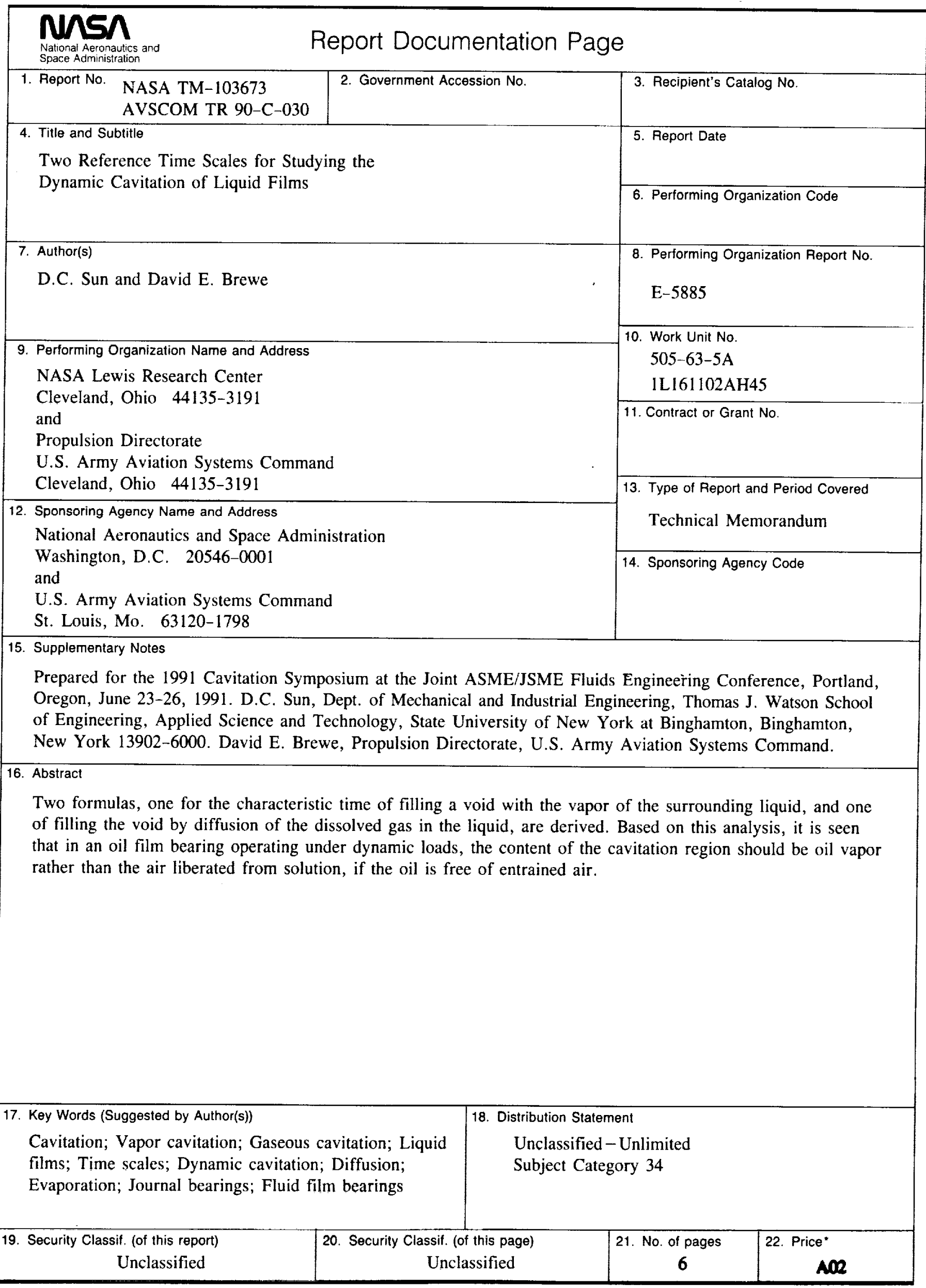

